The Sociology of Development and the Development of Sociology: Perspectives and Prospects in Social Anthropology and Sociology in Eastern Africa

A workshop on the above theme will be held from 26 to 29 August at Makerere University, Kampala, Uganda, under the chairmanship of Professor Raymond Apthorpe, to review some of the more general issues involved in Eastern African studies, to assess research priorities for the immediate future, and to consider work already carried out by the Makerere Institute of Social Research and Makerere College to date. It is hoped to discuss the extent to which social-anthropological and sociological studies have already contributed towards the formation of public policy, the contribution of 'applied' studies to the conceptual level of these disciplines, their present intellectual status in Eastern Africa, and plans for the future. The Workshop is planned to open immediately after a Political Science Workshop on a similar theme (23 to 25 August). Later in the year Social Psychology and then Demography will hold comparable Workshops.

\title{
International African Seminar on the Social Implications of Multilingualism in Eastern Africa
}

THE International African Institute is organizing the ninth in its series of International African Seminars, to be held at University College, Dar es Salaam, in December 1968. The subject of the Seminar will be 'The Social Implications of Multilingualism in Eastern Africa '. It will be held under the chairmanship of Professor Wilfred Whiteley and in association with the Survey of Language Use and Language Teaching in Eastern Africa. The Seminar will address itself to a range of problems which arise from the fact that the countries of Eastern Africa are multilingual societies. Some of these are concerned with ' language choice', others relate to language teaching and 'language planning'. The topics to be discussed by participants will include: theoretical problems and methods of research; social and political problems of multilingualism; implications of multilingualism in education; sociological and linguistic implications of developing technical vocabulaties and of assimilating loan words; problems of urban multilingualism.

The Institute is also preparing the tenth in the series of Seminars, all of which have been held with the aid of funds from the Ford Foundation. The University of Abidjan will act as host for this Seminar in December 1969. It will be concerned with the development of markets in West Africa. 